\title{
Application of active zein-based films with controlled release properties to control Listeria monocytogenes growth and lipid oxidation in fresh Kashar cheese
}

\author{
İlke Uysal Ünalan ${ }^{1}$, Iskender Arcan, Figen Korel, Ahmet Yemenicioğlu * \\ Department of Food Engineering, Faculty of Engineering, Izmir Institute of Technology, 35430, Gülbahçe Köyü, Urla, Izmir, Turkey
}

\section{A R T I C L E I N F O}

\section{Article history:}

Received 10 May 2013

Accepted 20 August 2013

Editor Proof Receive Date 10 September 2013

\section{Keywords:}

Zein

Composite

Controlled release

Active packaging

L. monocytogenes

\begin{abstract}
A B S T R A C T
The antimicrobial and antioxidant potential of zein and zein-wax composite films having different release profiles for lysozyme and mixture of lysozyme, catechin and gallic acid were tested on cold-stored fresh Kashar cheese inoculated with Listeria monocytogenes ATCC 7644. All lysozyme containing films prevented the increase of $L$. monocytogenes counts in Kashar cheese for 8 weeks at $4{ }^{\circ} \mathrm{C}$, but it was only the zein-wax composite films with sustained lysozyme-release rates which caused a significant reduction $(-0.4$ decimals) in initial microbial load of inoculated cheese samples. The mixture of catechin and gallic acid improved the in vitro antimicrobial effect of films against L. monocytogenes, but showed no considerable antimicrobial effect in cheese. However, the films containing catechin and gallic acid were effective in preventing oxidative changes in cheese. This study showed the possibility of increasing safety and quality of fresh cheeses by use of active packaging employing natural antimicrobial compounds and controlled release technology.

Industrial relevance: There has been a growing interest to develop the functional properties of packaging materials and to obtain packed foods with better shelf-life and quality. Active packaging incorporating antimicrobials is one of the most promising areas since application of this method can improve safety of foods by inhibiting pathogenic bacteria or controlling spoilage flora by using minimum amounts of active compounds. Recently, health concerns of consumers and environmental problems related to plastics increased the popularity of using natural antimicrobial substances in edible films and coatings. This work employs a GRAS status natural antimicrobial lysozyme and zein a major by-product of rapidly growing oil and bioethanol industries which can form self-standing films, coatings or casings. The results of this study showed the possibility of using flexible antimicrobial and antioxidant films with controlled release properties in diary industry.
\end{abstract}

(c) 2013 Elsevier Ltd. All rights reserved.

\section{Introduction}

There has been growing interest to develop the functional properties of packaging materials and obtain packed foods with better shelf-life and quality. Active packaging incorporating antimicrobials is one of the most promising areas since the application of this method can improve safety of foods by inhibiting pathogenic bacteria or controlling spoilage biota by using minimum amounts of active compounds (Appendini \& Hotchkiss, 2002). Antimicrobial packaging targets mainly the food surface on which microbiological changes occur most intensively (Appendini \& Hotchkiss, 2002). However, a sufficient antimicrobial effect could not be achieved unless the release rate of antimicrobial compounds from the packaging materials to food surface can be controlled properly by considering the physical and chemical properties of food, growth kinetics of target pathogenic or spoilage microorganisms, and the expected food shelf-life (Han, 2005).

\footnotetext{
* Corresponding author. Tel.: +90 232 7506292; fax: +90232 7506196.

E-mail address: ahmetyemenicioglu@iyte.edu.tr (A. Yemenicioğlu).

1 Present Addresses: Packaging Division, Department of Food, Environmental and Nutritional Sciences, University of Milan, Via Celoria 2, 20133, Milan, Italy.
}

In the literature, there are a variety of studies which aim to design active plastic, biodegradable or edible films employing different chemicals and natural antimicrobials. But health concerns of the consumers and environmental problems have caused a particular interest in using natural antimicrobial compounds in edible packaging materials (Appendini \& Hotchkiss, 2002; Han, 2005). The natural antimicrobial enzyme lysozyme obtained from hen egg white is one of the most potential candidates for antimicrobial packaging since it has a GRAS status and it shows good stability and activity in different films and food systems under refrigerated storage temperatures (Mecitoglu et al., 2006; Ünalan, Korel, \& Yemenicioğlu, 2011). Lysozyme shows antimicrobial activity mainly on Gram-positive bacteria by splitting the bonds between Nacetylmuramic acid and $\mathrm{N}$-acetylglucosamine of the peptidoglycan in their cell walls. Thus, the application of lysozyme in active packaging targets mainly inhibition of the major Gram-positive pathogenic bacteria, such as L. monocytogenes (Duan, Park, Daeschel, \& Zhao, 2007; Min, Harris, Han, \& Krochta, 2005). L. monocytogenes is a very critical food pathogen for dairy products due to its high incidence in raw milk and capacity to grow at refrigeration temperatures (Kozak, Balmer, Byrne, \& Fisher, 1996). Although fresh cheeses are mostly produced by using pasteurized milk, several listeriosis outbreaks associated with the 
consumption of cheeses made from pasteurized milk have also been reported due to improper pasteurization or post-contamination (de Castro et al., 2012; Jackson et al., 2011; Johnsen, Lingaas, Torfoss, Strøm, \& Nordøy, 2010; Yde et al., 2012).

Lysozyme has recently been tested extensively in different edible materials including zein, soy protein, carrageenan, whey protein, chitosan, alginate and pullulan (Joerger, 2007; Mendes de Souza, Fernández, López-Carballo, Gavara, \& Hernández-Muñoz, 2010). However, there are very limited studies related to the design of the edible films with controlled release properties for lysozyme. For example, Mendes de Souza et al. (2010) developed sodium caseinate films of which lysozyme release profiles could be changed by modifying $\mathrm{pH}$ and the amount of crosslinking agents such as $\mathrm{CaCl}_{2}$, transglutaminase and glyoxal used in film-making. Park, Daeschel, and Zhao (2004) also formed chitosanlysozyme composites and achieved different release rates for lysozyme by changing the amount of the enzyme within the composite structure. Arcan and Yemenicioğlu (2013) also showed the possibility of controlling release rates of lysozyme in zein-wax composite and zein-fatty acid blend films, and they reported that the hydrophobicity and morphology and the resulting lysozyme release profiles of zein films could easily be modified by using different types of waxes such as carnauba wax, candelilla wax or beeswax and fatty acid oleic acid in film-making. The phenolic compounds used both as plasticizer and antioxidant agent in zein-based films also effect the morphologies and release profiles of films depending on their molecular weight and chemical structure (Arcan and Yemenicioğlu, 2011, 2013). It was reported by Arcan and Yemenicioglu $(2011,2013)$ that the flavonoid catechin reduced zein film porosity and contributed to the reduction of phenolic and lysozyme-release rates when it was used for plasticizing zein films. In contrast, low molecular weight (MW) phenolic acid gallic acid increased the zein film porosity and phenolic release rates when it was employed in film plasticization (Alkan et al., 2011). Both catechin and gallic acid are effective zein plasticizers and antioxidants, but gallic acid is additionally known with its potent antimicrobial activity on critical pathogenic bacteria including L. monocytogenes (Arcan \& Yemenicioğlu, 2011). In the present work the antimicrobial and antioxidant potential of active zein and zein-wax composite films having different release profiles for lysozyme and mixture of lysozyme and phenolic compounds catechin and gallic acid have been tested on coldstored fresh Kashar cheese inoculated with L. monocytogenes. The present work makes a significant contribution in active packaging of dairy products since it is the first study in the literature related to control of L. monocytogenes in fresh cheeses by use of lysozyme containing active edible packaging employing controlled release technology.

\section{Materials and methods}

\subsection{Materials}

Maize zein (batch number: 058K0093), $(+)$-catechin hydrate ( $\geq 98 \%$ ), gallic acid, Micrococcus lysodeikticus, carnauba wax (No.1, refined), beeswax, and candelilla wax were supplied from Sigma Chem. Co. (St. Louis, Mo, USA). Soybean L- $\alpha$-lecithin and glycerol were from Merck (Darmsdadt, Germany). All other chemicals were reagent grade. Fresh hen eggs used in production of lysozyme were obtained from a supermarket in Izmir (Turkey). Fresh Kashar cheese (Pınar Milk Company, İzmir, Turkey) was obtained from a supermarket and sliced with using a stainless steel guillotine type commercial cheese slicer under aseptic conditions.

\subsection{Production of lysozyme}

Lysozyme was produced by the selective precipitation of egg white proteins other than the enzyme according to the method described by Mecitoglu et al. (2006). The enzyme was lyophilized by using a freeze drier (Labconco, FreeZone, 6 1, Kansas City, MO, USA) and stored at $-18{ }^{\circ} \mathrm{C}$ until it was used in film-making. The specific activity of lysozyme produced by this method was $40477 \mathrm{U} / \mathrm{mg}$ protein. The purity of the partially purified lysozyme was 2-fold lower than that of pure commercial lysozyme (Sigma L6876, St. Louis, Mo, USA). During determination of their specific activities both enzyme was dissolved in distilled water and tested for their enzyme activities (see Section 2.5.1) and protein contents with the Bradford method using bovine serum albumin as standard.

\subsection{Preparation of films}

Zein films were prepared as described in Padgett, Han, and Dawson (1998). Briefly, $1.4 \mathrm{~g}$ of zein was dissolved with $8.1 \mathrm{~mL}$ of ethanol (96\%) by mixing slowly with a magnetic stirrer for $25 \mathrm{~min}$. Glycerol $(0.4 \mathrm{~mL})$ was then added to the medium as a plasticizer. The temperature of the mixture was then increased until it started to boil. The mixing was ceased and the solution was cooled to the room temperature after it had been boiled for $5 \mathrm{~min}$. After that, the lysozyme $(11.7 \mathrm{mg} / \mathrm{g}$ filmforming solution) used as the antimicrobial agent, catechin and gallic acid (50 mg/g film-forming solution) used as the antioxidant agents and additional plasticisers to obtain highly flexible zein films (Arcan \& Yemenicioğlu, 2011), and lecithin $(5 \%(\mathrm{w} / \mathrm{w})$ of zein) used as the emulsifier (for wax containing films only) were added into film-forming solutions. The mixtures were then homogenized (Heidolph, Germany, rotor $\Phi=6.6 \mathrm{~mm}$ tip) at $10,000 \mathrm{rpm}$ for $4 \mathrm{~min}$, and $4.3 \mathrm{~g}$ portions of the homogenized film-forming solutions were poured into the glass templates $(\mathrm{W} \times \mathrm{L} \times \mathrm{H}: 8.5 \times 8.5 \times 0.4 \mathrm{~cm})$ placed on a balance. The films were then dried for $19 \pm 2 \mathrm{~h}$ at $25^{\circ} \mathrm{C}$ in an incubator. This procedure was also used to obtain zein-wax composite films by adding carnauba wax, candelilla wax or beeswax into film-forming solutions at $5 \%(w / w)$ of zein. To ease their melting and homogenization, the waxes were added just before the initiation of heating of film-making solutions. The final concentrations of lysozyme, catechin and gallic acid in dried films were $0.7,3$ and $3 \mathrm{mg} / \mathrm{cm}^{2}$, respectively.

\subsection{Scanning electron microscopy (SEM) and mechanical properties of films}

The cross-sectional morphology of the selected films was determined by using SEM (Philips XL 30S FEG, FEI Company, Netherlands) under high vacuum mode at an operating voltage varying between 2 and $3 \mathrm{kV}$. Films were prepared for SEM by crashing, following freezing in liquid nitrogen. The samples were then gold-coated with a sputter coater (Emitech K550X, Quorum Technologies Inc.,UK) under $15 \mathrm{~mA}$ for $60 \mathrm{~s}$. The thickness of the films used in mechanical tests was also measured from SEM cross-sectional views of films by using Scandium software (Olympus Soft Imaging Solutions GmbH, Münster, Germany). The elongation at break values of the films were measured using a Texture Analyser TA-XT2 (Stable Microsystems, Godalming, UK) according to the ASTM Standard Method D 882-02 (ASTM, 2002). For conditioning of the films used in mechanical testing, the drying procedure described in film preparation was modified as $24 \mathrm{~h}$ at $25^{\circ} \mathrm{C}$ and $50 \% \mathrm{RH}$ using a controlled test cabinet (TK 120, Nüve, Turkey). Films were cut into $5-\mathrm{mm}$ wide and $80-\mathrm{mm}$ long strips. The initial grip distance was $50 \mathrm{~mm}$ and crosshead speed was $50 \mathrm{~mm} / \mathrm{min}$. At least seven replicates of each film were tested.

2.5. Release profiles and in vitro antimicrobial and antioxidant activity of zein and zein-wax composite films

\subsubsection{Lysozyme release profiles of films}

The release tests of zein and zein-wax composite films were conducted in distilled water at $4{ }^{\circ} \mathrm{C}$ with continuous shaking during the incubation period. Briefly, $4 \times 4 \mathrm{~cm}$ pieces of films were placed into glass petri dishes containing $50 \mathrm{~mL}$ of deionized water. The dishes were kept at $4{ }^{\circ} \mathrm{C}$ in an incubator and shaken with an orbital shaker 
working at $80 \mathrm{rpm}$. The release tests were conducted until the equilibrium reached for release of lysozyme or an insignificant increase was observed in lysozyme activity. The lysozyme activity was monitored by taking $0.1 \mathrm{~mL}(\times 3)$ aliquots from the release test medium at different time intervals. The enzyme activities in the collected aliquots were determined spectrophotometrically at $660 \mathrm{~nm}$ by using Shimadzu spectrophotometer (Model 2450, Japan) equipped with a constant cell holder at $30^{\circ} \mathrm{C}$. The reaction mixtures were formed by mixing $0.1 \mathrm{~mL}$ of release test medium with $2.4 \mathrm{~mL}$ of Micrococcus lysodeikticus solution $(0.26 \mathrm{mg} / \mathrm{mL}$ ) prepared in $0.05 \mathrm{M}$, pH $7.0 \mathrm{Na}$-phosphate buffer. The enzyme activities were calculated from the slopes of initial linear portions of absorbance vs. time curves and expressed as unit (U) which was defined as 0.001 change in absorbance in $1 \mathrm{~min}$. All calculations were corrected by considering the activity removed by the collected aliquots during sampling. The total lysozyme activity released from each film corresponded to maximum units released per $\mathrm{cm}^{2}$ of the films $\left(\mathrm{U} / \mathrm{cm}^{2}\right)$ at the equilibrium. All activity measurements were conducted three times. The release curves were formed by plotting the calculated released activities $\left(\mathrm{U} / \mathrm{cm}^{2}\right)$ vs. time (h). The initial release rates of lysozyme were determined from the slope of the initial linear portion of release curve. The release rates were expressed as $\mathrm{U} / \mathrm{cm}^{2} / \mathrm{h}$.

\subsubsection{Phenolic release profiles of films}

To determine the phenolic release profiles of films, the release tests were conducted in water as described at Section 2.5.1. The soluble phenolic content was monitored in release medium by taking $0.1 \mathrm{~mL}(\times 3)$ aliquots from the release test medium at different time intervals until the phenolic release reached an equilibrium. The phenolic content was determined spectrophotometerically at $765 \mathrm{~nm}$ according to the classical Folin-Ciocalteu method of Singleton and Rossi (1965). The total soluble phenolic contents released from the films were expressed as $\mathrm{mg}$ gallic acid per $\mathrm{cm}^{2}$ of the films $\left(\mathrm{mg} / \mathrm{cm}^{2}\right)$ using the calibration curve prepared by gallic acid. All concentration measurements were conducted three times. The release curves were formed by plotting the calculated released phenolic contents $\left(\mathrm{mg} / \mathrm{cm}^{2}\right) v s$. time $(\mathrm{h})$. The initial phenolic release rates were determined from the slope of the initial linear portion of release curve. The release rates were expressed as $\mathrm{mg} / \mathrm{cm}^{2} / \mathrm{h}$.

\subsubsection{Antioxidant activity of films}

The antioxidant activity of films was measured by determining the oxygen radical absorbance capacity (ORAC) values of release medium when the phenolic release reached the equilibrium. The ORAC method was applied by slightly modifying the procedure given by $\mathrm{Xu}$ and Chang (2007). Briefly, $20 \mu \mathrm{L}$ of release medium was pipetted into a 96-well plate (black). Then, $200 \mu \mathrm{L}$ of $0.096 \mu \mathrm{M}$ fluorescein solution prepared in PBS (75 mM, pH 7.4) was added into each well and the mixture was incubated at dark for $20 \mathrm{~min}$ at $37^{\circ} \mathrm{C}$. Adding $20 \mu \mathrm{L}$ of $100 \mathrm{mM}$ 2,2'-azobis(2-amidino-propane) dihydrochloride (AAPH) prepared in PBS started the reaction. The fluorescence of reaction mixture was monitored periodically for $40 \mathrm{~min}$ at the excitation wavelength of $485 \mathrm{~nm}$ and emission wavelength of $520 \mathrm{~nm}$ by using a Varioskan Flash spectrophotometer (3001, Finland). The ORAC value of samples were calculated by determining the trolox equivalent of values obtained by subtracting the area of quenching curve of samples from that of blank formed by using distilled water instead of sample. The measurements were conducted as three replicates and ORAC values of films were calculated as $\mu \mathrm{mol}$ Trolox equivalents per $\mathrm{cm}^{2}$ of films ( $\mu \mathrm{mol}$ Trolox $/ \mathrm{cm}^{2}$ ).

\subsubsection{Antimicrobial activity of films}

Antimicrobial activity of films was tested against $L$. monocytogenes ATCC 7644 maintained at $-80^{\circ} \mathrm{C}$. The inoculum of microorganism was prepared in peptone water $(0.1 \%)$ using a 48 -h culture of $L$. monocytogenes growth on Oxford Listeria Selective Agar (Merck, Darmstad, Germany) with Oxford Listeria Selective Supplement containing Cycloheximide (Merck, Darmstad, Germany) incubated at $37{ }^{\circ} \mathrm{C}$, and the cell concentration was set to 0.7 McFarland unit $\left(50 \times 10^{6} \mathrm{CFU} \mathrm{mL}{ }^{-1}\right)$. For antimicrobial tests, 16 disks $(1.3 \mathrm{~cm}$ in diameter) from each type of film were prepared by a cork borer. A total of 15 disks were selected randomly and used in tests by placing three disks per petri dish containing nutrient agar which had been previously inoculated with $0.1 \mathrm{~mL}$ of microbial culture. The petri dishes were firstly incubated at $+4{ }^{\circ} \mathrm{C}$ for $6 \mathrm{~h}$ to prevent rapid diffusion of the antimicrobial agents, and then incubated at $37^{\circ} \mathrm{C}$ for $36 \mathrm{~h}$. The diameter of the zones formed was measured by using a caliper. The results were expressed as average zone area $\left(\mathrm{mm}^{2}\right)$.

\subsection{Active packaging of fresh Kashar cheese with zein and zein-wax composite films}

\subsubsection{Inoculation of cheese slices with L. monocytogenes}

The L. monocytogenes was activated by transferring $0.2 \mathrm{~mL}$ of the frozen culture $\left(-80{ }^{\circ} \mathrm{C}\right)$ to $20 \mathrm{~mL}$ of Tryptic soy broth (Merck, Darmstad, Germany) containing $0.6 \%$ yeast extract (Fluka, Steinheim, Spain) (TSBYE), and incubating this broth at $37{ }^{\circ} \mathrm{C}$ for $21 \mathrm{~h}$. The culture was sub-cultured twice to reach $1 \times 10^{8} \mathrm{CFU} \mathrm{\textrm {mL } ^ { - 1 }}$. One-mL aliquot of the culture was diluted with buffered peptone water (Merck, Darmstad, Germany) to obtain an inoculum of $1 \times 10^{7} \mathrm{CFU} \mathrm{mL} \mathrm{m}^{-1}$.

Cheese slices $(4 \times 8.3 \mathrm{~cm}$ pieces with a thickness of $0.7 \mathrm{~mm})$ were placed on sterile disposable petri dishes kept in a safety cabinet. Then, $0.125 \mathrm{~mL}$ of inoculum $\left(10^{7} \mathrm{CFU} \mathrm{mL} \mathrm{m}^{-1}\right)$ was pipetted on surfaces of each slice and spread on their full surfaces with a sterile rod. The inoculated slices were kept $15 \mathrm{~min}$ within the safety cabinet to let the cheese surface absorb the inoculum. The slices were then turned back within petri dishes and the same inoculation procedure was performed for their other surface. The slices were once more kept for 15 min within the safety cabinet and then immediately used in active packaging application.

\subsubsection{Application of films on cheese slices}

The zein and zein-carnauba wax composite films employed in active packaging were prepared as described in Section 2.3. The films were cut into $4 \times 8.3 \mathrm{~cm}$ pieces and placed at both sides of Kashar cheese slices at the same size. The cheese slices coated with the films at both sides were first wrapped with a commercial stretch plastic film and then with an aluminum foil to ensure the tight contact among films and the cheese slice. Afterwards, the packs were stored in a refrigerated incubator at $4{ }^{\circ} \mathrm{C}$ and analyzed at different time intervals for microbial load and oxidative stability. The five different groups used in active packaging and their labeling were as follows: (1) Samples without any zein films: Uncoated, (2) Samples coated with zein films: Zein film [Control]; (3) Samples coated with zein films containing lysozyme $\left(0.7 \mathrm{mg} / \mathrm{cm}^{2}\right)$ : Zein film [lysozyme], (4) Samples coated with zein films containing catechin $\left(3.0 \mathrm{mg} / \mathrm{cm}^{2}\right)$, gallic acid $\left(3.0 \mathrm{mg} / \mathrm{cm}^{2}\right)$, and lysozyme $\left(0.7 \mathrm{mg} / \mathrm{cm}^{2}\right)$ : Zein film [catechin + gallic acid + lysozyme]; (5) Samples coated with zein-carnauba wax composite films containing catechin $\left(3.0 \mathrm{mg} / \mathrm{cm}^{2}\right)$, gallic acid $\left(3.0 \mathrm{mg} / \mathrm{cm}^{2}\right)$, lysozyme $\left(0.7 \mathrm{mg} / \mathrm{cm}^{2}\right)$, carnauba wax $(5 \%)$ and lecithin (5\%): Zein-carnauba wax composite film [catechin + gallic acid + lysozyme].

\subsubsection{Microbiological analysis of actively packed cheese slices}

The samples were analyzed just following the packaging and at 7th, 14th, 28th and 56th days of cold-storage to determine L. monocytogenes counts. A portion $(25 \mathrm{~g}$ ) of each sample was placed into a separate sterile stomacher bag with $225 \mathrm{~mL}$ sterile $0.1 \%$ peptone water and immediately homogenized using a stomacher (BagMixer ${ }^{\circledR} 400$, Interscience, France) for $180 \mathrm{~s}$. The serial decimal dilutions were prepared from this homogenate and appropriate dilutions $(0.1 \mathrm{~mL})$ were spread plated onto Oxford Listeria Selective Agar (Merck, Darmstad, Germany) with Oxford Listeria Selective Supplement containing Cycloheximide (Merck, Darmstad, Germany). The plates were incubated at $37{ }^{\circ} \mathrm{C}$ for $48 \mathrm{~h}$ and small black colonies with halos on the plates were enumerated. The counts were performed in duplicate plates. The two separate samples 
for each of the five different groups specified at Section 2.6.2 were analyzed at each sampling day. Microbiological counts were converted to $\log \mathrm{CFU} \mathrm{g^{-1 }}$ and the means and standard deviations were calculated $(\mathrm{n}=2)$.

\subsubsection{Monitoring lipid oxidation in actively packed cheese slices}

The antioxidant potentials of developed films were determined at 0th, 7th, 14th, 21th, 28th and 35th days of cold-storage by monitoring lipid oxidation in cheese samples with the thiobarbituric acid (TBA) assay as described by Bekhit, Geesink, Ilian, Morton, and Bickerstaffe (2003). The samples used for lipid oxidation tests were prepared as described at Section 2.6.2, but the cheese slices were not inoculated with $L$. monocytogenes for the safety of analysts. For analysis, 10-g sample was homogenized in a Waring blender using a mini jar for $3 \mathrm{~min}$ at high speed with $50 \mathrm{~mL}$ of $0.38 \%$ TBA and $15 \%$ trichloroacetic acid prepared in $0.25 \mathrm{~N} \mathrm{HCl}$ solution. Aliquots $(5 \mathrm{~mL}$ ) obtained from homogenate were incubated in a water bath at $95{ }^{\circ} \mathrm{C}$ for $15 \mathrm{~min}$ for color development. Samples were cooled for $10 \mathrm{~min}$ in an ice water bath and then centrifuged at $4500 \times g$ for $25 \mathrm{~min}$. The absorbances of the samples were measured at $532 \mathrm{~nm}$ with a spectrophotometer. A standard curve was determined using dilutions of $1 \mathrm{mM} 1,1,3,3$ tetraethoxypropane (TEP) and the results were expressed as mg malondialdehyde (MDA) per kg cheese. MDA extinction coefficient calculated from standard curve of TEP was $1.56 \times 10^{5} \mathrm{M}^{-1} \mathrm{~cm}^{-1}$. The experiments were performed in duplicate by taking three readings per replicate.

\subsection{Statistical analysis}

Analysis of variance (ANOVA) was applied using Minitab 14 (Minitab Inc., State College, PA) to determine the effects of storage time and different packaging treatments on the growth of L. monocytogenes and oxidative stability in Kashar cheese. Multiple comparisons of means were performed using Fisher's Least Significant Difference (LSD) test with a level of $95 \%$ confidence interval.

\section{Results and discussion}

3.1. Release profiles and active properties of zein and zein-wax composite films

\subsubsection{Lysozyme and phenolic release profiles of films}

The extensive preliminary studies and mechanical tests indicated that the use of the mixture catechin and gallic acid as phenolic plasticizers, each at the concentration of $3 \mathrm{mg} / \mathrm{cm}^{2}$, successfully increased the elongation at break values of standard glycerol plasticized zein films from $4 \%$ to $196 \%$ without increasing film porosity which was an important factor effecting lysozyme and phenolic release profiles of films. In fact, a limited reduction in film porosity was observed for both films of zein and its composites plasticized by mixture of catechin and gallic acid (Fig. 1A-C). The release curves obtained in distilled water at $4{ }^{\circ} \mathrm{C}$ clearly showed the considerably different lysozyme and phenolic release profiles of zein and zein-wax composite films (Fig. 2A and B). The lysozyme-release rates of zein-wax composites containing mixture of catechin and gallic acid were 7.5- to 8.5-fold lower than those of lysozyme containing zein films and zein films containing lysozyme, catechin and gallic acid (Table 1). The lack of any considerable differences between lysozyme-release rates of zein films and zein films containing catechin and gallic acid suggested that the major factor causing the sustained lysozyme-release rates was not the limited reduction in film porosity by use of phenolic plasticizers. It appeared that the reduced lysozyme-release rates were related to the increased film hydrophobicity and tortuosity originated form waxes incorporated into zein films during composite film-making. However, there were no considerable effects of using different types of waxes such as carnauba wax, candelilla wax, and beeswax on lysozyme-release rates of composite films. On the

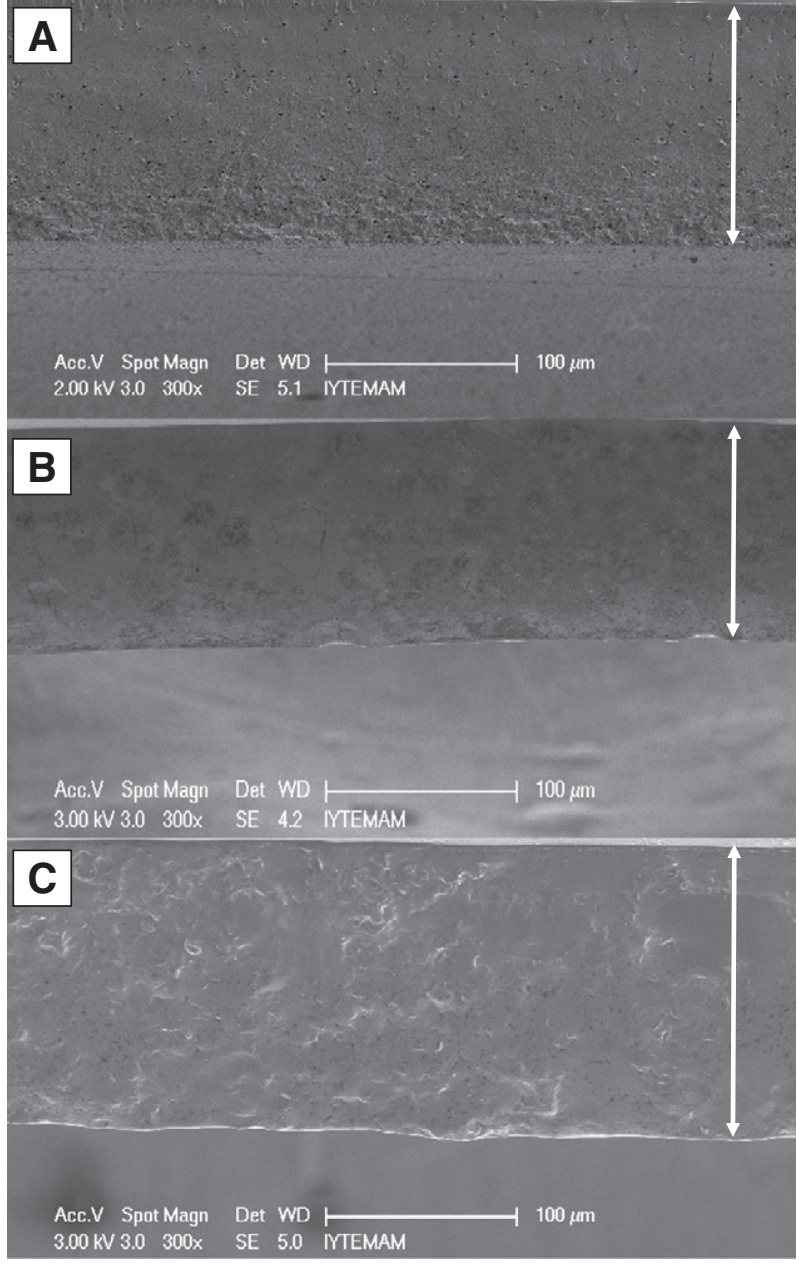

Fig. 1. Cross-sectional SEM images of different films: Control zein film (A); zein film containing lysozyme, catechin and gallic acid (B); zein-carnauba wax composite film containing lysozyme, catechin and gallic acid (C) (arrows indicate the cross-section area of the films at $\times 300$ magnification).

other hand, the total amount of enzyme released from lysozyme, catechin and gallic acid containing zein films at the equilibrium was significantly higher than that released from lysozyme, catechin and gallic acid containing zein-wax composite films $(P<0.05)$. This result suggested some limited trapping of hydrophilic lysozyme within the aggregated hydrophobic wax particles of composite films.

The phenolic release profiles of zein and zein-wax composite films were also considerably different (Fig. 2B). The highest phenolic release rates were observed for zein films while zein-beeswax and zeincandelilla wax composite films showed the lowest phenolic release rates. The zein-carnauba wax films had an intermediate phenolic release rate which was almost 1.7-fold higher than those of the other composite films, but 3.4-fold lower than that of zein films. These results clearly showed the effects of composite film-making and wax type used in composites on phenolic release rates. It appeared that the melting point (MP) of waxes is the primary factor affecting the phenolic release profiles. The carnauba wax has a high MP between 82 and $86{ }^{\circ} \mathrm{C}$, while candelilla wax and beeswax have lower MPs changing between 68.5 and $72.5^{\circ} \mathrm{C}$ and 62 and $66{ }^{\circ} \mathrm{C}$, respectively. The lower MP of waxes increased the efficiency of mixing and homogenization of zein with the extremely hydrophobic waxes, and this was effective in uniformly distributing and reducing sizes of wax particles within the film matrix. Recent studies of Arcan and Yemenicioğlu (2013) clearly showed the better distribution of candelilla wax and beeswax in zein film matrix than carnauba wax which formed extensive wax aggregates within the composite films. Thus, it appeared that the increased contact and 

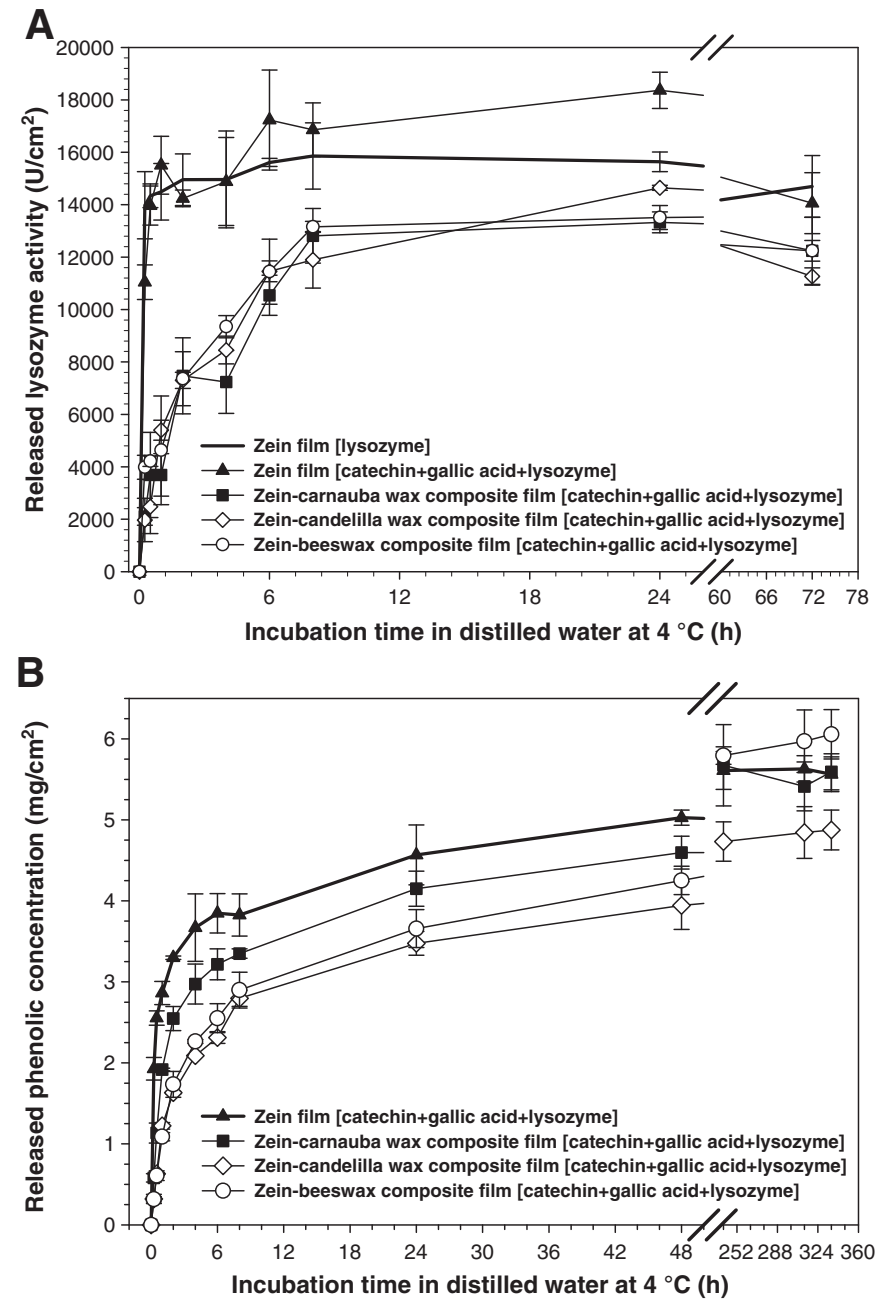

Fig. 2. Release profiles of lysozyme (A) and phenolic compounds (B) from zein-based films (concentration of lysozyme: $0.7 \mathrm{mg} / \mathrm{cm}^{2}$, concentrations of catechin and gallic acid: $3.0 \mathrm{mg} / \mathrm{cm}^{2}$, concentration of waxes and lecithin: $5 \%(w / w)$ of zein).

distribution of phenolic compounds within the wax fraction might be the primary factor causing lower phenolic release rates of candelilla wax and beeswax containing films than carnauba wax containing films in water. On the other hand, the total released phenolic contents of zein and zein-wax composite films at the equilibrium showed that 82 to $93 \%$ of total incorporated phenolics were free and existed in soluble form within the film matrix. The incorporation of waxes into zein films and formation of composites increased the total amount of phenolic compounds released from composite films at the equilibrium $(P<0.05)$. It appeared that the hydrophobic wax fraction within the films did not contain hydrogen bonding groups to bind and immobilize phenolic compounds chemically. Thus, slow release of phenolic compounds from the hydrophobic composite structure continued and solubilized phenolic content at the equilibrium reached to a higher level than those of zein films. In contrast, zein films lacking wax have more carbonyl groups than zein-wax composites and they create more $\mathrm{H}$ bonding with phenolic compounds to bind and immobilize them. These hypotheses compared well with the recent studies which investigated release profiles and interaction of phenolic compounds including catechin and gallic acid with the zein film matrix (Alkan et al., 2011; Arcan \& Yemenicioğlu, 2013).

\subsubsection{Antioxidant and antimicrobial activity of films}

The free radical scavenging-based antioxidant activities of zein and zein-wax composite films were determined by the ORAC method. The ORAC values determined in water used as release medium varied between 60 and $67 \mu \mathrm{mol}$ Trolox $/ \mathrm{cm}^{2}$ and showed parallelism with the total released phenolic contents of films at the equilibrium. The ORAC values of catechin and gallic acid containing zein-wax composite films were found significantly higher than those of the zein films containing these phenolic compounds $(P<0.05)$. This result showed the difference in phenolic release profiles and total antioxidant activities of zein and zein-wax composite films.

Considerable differences were also determined in antimicrobial properties of different films against $L$. monocytogenes tested by the classical zone inhibition test. The largest clear zones were determined for zein films containing mixture of catechin and gallic acid, and zein and zein-carnauba wax composite films containing mixture of lysozyme, catechin and gallic acid, while zein films containing only lysozyme showed the minimum antimicrobial activity. These results clearly indicated the contribution of phenolic compounds to in vitro antimicrobial activity of films. However, it should be noted that these results did not indicate greater antimicrobial potential of phenolic compounds than lysozyme. The catechin (MW: 290.3) and gallic acid (MW: 170.1) are low molecular weight compounds and they can migrate much more rapidly than lysozyme (MW: 14307) in agar. This caused greater zones in presence of phenolic compounds. In contrast, the lower antimicrobial activity of zein-candelilla wax and zein-beeswax films than zein-carnauba

Table 1

Some kinetic parameters determined from release curves, and antimicrobial and antioxidant potential of zein based films.

\begin{tabular}{|c|c|c|c|c|c|c|c|c|}
\hline \multicolumn{3}{|c|}{ Film compositions $\left(\mathrm{mg} / \mathrm{cm}^{2}\right)$} & \multirow{2}{*}{$\begin{array}{l}\text { Initial lysozyme release } \\
\text { rate }\left(\mathrm{U} / \mathrm{cm}^{2} / \mathrm{h}\right)\end{array}$} & \multirow{2}{*}{$\begin{array}{l}\text { Total released lysozyme } \\
\text { activity }\left(\mathrm{U} / \mathrm{cm}^{2}\right)\end{array}$} & \multirow{2}{*}{$\begin{array}{l}\text { Initial phenolic release } \\
\text { rate }\left(\mathrm{mg} / \mathrm{cm}^{2} / \mathrm{h}\right)\end{array}$} & \multirow{2}{*}{$\begin{array}{l}\text { Total released phenolic } \\
\text { content } \\
\left(\mathrm{mg} / \mathrm{cm}^{2}\right)\end{array}$} & \multirow{2}{*}{$\begin{array}{l}\text { Antioxidant activity } \\
\left(\mu \mathrm{mol} \text { Trolox } / \mathrm{cm}^{2}\right)\end{array}$} & \multirow{2}{*}{$\begin{array}{l}\text { Antimicrobial activity } \\
\text { (zone area as } \mathrm{mm}^{2} \text { ) }\end{array}$} \\
\hline Lysozyme & Catechin & Gallic acid & & & & & & \\
\hline \multicolumn{9}{|l|}{ Zein film } \\
\hline 0.7 & - & - & $34132(0-0.5)^{a}$ & $15859 \pm 1265 \mathrm{ab}^{\mathrm{b}}$ & - & - & - & $98 \pm 14 a$ \\
\hline \multicolumn{9}{|l|}{ Zein film } \\
\hline- & 3.0 & 3.0 & - & - & - & - & - & $254 \pm 21 c$ \\
\hline \multicolumn{9}{|l|}{ Zein Film } \\
\hline 0.7 & 3.0 & 3.0 & $31182(0-0.5)$ & $18365 \pm 609 a$ & $5.63(0-0.5)^{\mathrm{c}}$ & $4.9 \pm 0.2 c$ & $60 \pm 1 c$ & $232 \pm 50 \mathrm{bc}$ \\
\hline \multicolumn{9}{|c|}{ Zein-carnauba wax composite film } \\
\hline 0.7 & 3.0 & 3.0 & $3953(0-2)$ & $13327 \pm 399 b$ & $1.65(0-2)$ & $5.4 \pm 0.1 \mathrm{ab}$ & $63 \pm 2 b$ & $249 \pm 22 c$ \\
\hline \multicolumn{9}{|c|}{ Zein-candelilla wax composite film } \\
\hline 0.7 & 3.0 & 3.0 & $4090(0-2)$ & $14645 \pm 98 b$ & $0.93(0-2)$ & $5.6 \pm 0.1 \mathrm{a}$ & $67 \pm 1 a$ & $151 \pm 63 \mathrm{ab}$ \\
\hline \multicolumn{9}{|c|}{ Zein-beeswax composite film } \\
\hline 0.7 & 3.0 & 3.0 & $4087(0-2)$ & $13751 \pm 1914 b$ & $0.92(0-2)$ & $5.2 \pm 0.1 b$ & $66 \pm 1 \mathrm{ab}$ & $166 \pm 54 a b$ \\
\hline
\end{tabular}

a Time periods ( $h$ ) of data used in best fit. $\mathrm{R}^{2}$ value of the best fitted curves varies between 0.7226 and 0.8938 .

b Different letters in each column show significant difference at $P<0.05$.

c Time periods (h) of data used in best fit. $R^{2}$ value of the best fitted curves varies between 0.8656 and 0.9633 . 
Table 2

Antimicrobial effects of active packaging on L. monocytogenes inoculated Kashar cheese.

\begin{tabular}{|c|c|c|c|c|}
\hline \multicolumn{5}{|c|}{ L. monocytogenes counts during storage at $4{ }^{\circ} \mathrm{C}(\log \mathrm{CFU} / \mathrm{g})^{\mathrm{a}}$} \\
\hline Day 0 & Day 7 & Day 14 & Day 28 & Day 56 \\
\hline $\begin{array}{l}\text { Uncoated } \\
5.53 \pm 0.07^{\mathrm{a}, \mathrm{A}}\end{array}$ & $6.02 \pm 0.23^{\mathrm{a}, \mathrm{A}}$ & $6.16 \pm 0.01^{\mathrm{a}, \mathrm{A}}$ & $6.15 \pm 0.01^{\mathrm{a}, \mathrm{A}}$ & $8.13 \pm 0.59^{\mathrm{a}, \mathrm{B}}$ \\
\hline $\begin{array}{l}\text { Zein film [contro } \\
5.69 \pm 0.16^{\mathrm{a}, \mathrm{A}}\end{array}$ & $5.86 \pm 0.21^{\mathrm{a}, \mathrm{AB}}$ & $6.08 \pm 0.04^{\mathrm{a}, \mathrm{BC}}$ & $6.25 \pm 0.02^{\mathrm{a}, \mathrm{C}}$ & $7.88 \pm 0.04^{\mathrm{a}, \mathrm{D}}$ \\
\hline $\begin{array}{l}\text { Zein film [lysozy } \\
5.67 \pm 0.11^{\mathrm{a}, \mathrm{A}}\end{array}$ & $\begin{array}{l}\text { me] } \\
5.94 \pm 0.14^{\mathrm{a}, \mathrm{A}}\end{array}$ & $5.85 \pm 0.03^{\mathrm{b}, \mathrm{A}}$ & $5.86 \pm 0.00^{\mathrm{b}, \mathrm{A}}$ & $5.86 \pm 0.00^{\mathrm{b}, \mathrm{A}}$ \\
\hline $\begin{array}{l}\text { Zein film [ catech } \\
5.96 \pm 0.12^{\mathrm{a}, \mathrm{A}}\end{array}$ & $\begin{array}{c}n+\text { gallic acid }+ \\
6.01 \pm 0.00^{\mathrm{a}, \mathrm{A}}\end{array}$ & $\begin{array}{l}\text { lysozyme] } \\
5.87 \pm 0.08^{\mathrm{b}, \mathrm{A}}\end{array}$ & $5.79 \pm 0.01^{\mathrm{b}, \mathrm{A}}$ & $5.75 \pm 0.28^{\mathrm{b}, \mathrm{A}}$ \\
\hline $\begin{array}{l}\text { Zein-carnauba } \\
6.02 \pm 0.04^{\mathrm{a}, \mathrm{A}}\end{array}$ & $\begin{array}{l}\text { vax composite film } \\
5.79 \pm 0.17^{\mathrm{a}, \mathrm{AB}}\end{array}$ & $\begin{array}{l}\text { catechin + gallic } \\
5.66 \pm 0.01^{\mathrm{c}, \mathrm{AB}}\end{array}$ & $\begin{array}{c}\text { acid + lysozyme] } \\
5.60 \pm 0.07^{\mathrm{c}, \mathrm{B}}\end{array}$ & $5.59 \pm 0.04^{\mathrm{b}, \mathrm{B}}$ \\
\hline $\begin{array}{l}\text { a-c Values withi } \\
\text { different }(P>0 \\
\text { A-D Values with } \\
\text { different }(P>0 \\
\text { a Initial inocula } \\
\text { b Shows film ce }\end{array}$ & $\begin{array}{l}\text { n each storage tir } \\
05 \text { ). } \\
\text { in each treatmen } \\
05 \text { ). } \\
\text { tion level was } 5 \text { ld } \\
\text { mpositions descr }\end{array}$ & $\begin{array}{l}\text { ne followed by } \\
\text { t followed by th } \\
\text { ibed in Section } 2\end{array}$ & $\begin{array}{l}\text { same letter are } \\
\text { same letter are }\end{array}$ & $\begin{array}{l}\text { not significant } \\
\text { not significant }\end{array}$ \\
\hline
\end{tabular}

wax films could be related with slower phenolic release rates of these films than zein-carnauba wax composites since these films have similar lysozyme-release rates.

\subsection{Active packaging of fresh Kashar cheese with zein and zein-carnauba wax composite films}

\subsubsection{Antimicrobial potential of films against L. monocytogenes inoculated on Kashar cheese}

The lysozyme, catechin and gallic acid containing zein-carnauba wax composites, which showed higher in vitro antimicrobial activity than the other lysozyme, catechin and gallic acid containing composites and standard lysozyme containing zein films, were employed in the food application. The results of the microbiological tests showing $L$. monocytogenes counts of inoculated cheeses packed with different films and coldstored for 56 days are displayed in Table 2. The L. monocytogenes counts of uncoated and zein coated controls did not change significantly in the first 28 days of cold storage, but the counts of these controls increased almost 1.6-2.0 decimals between the 28th and 56th days of cold-storage. In contrast, no significant increase occurred in the L. monocytogenes counts of cheese samples actively packed with zein or zein-carnauba wax composite films containing lysozyme alone or in combination with catechin and gallic acid. These results clearly showed the effectiveness of all lysozyme containing films in preventing growth of contaminated $L$. monocytogenes in cheeses. On the other hand, the lack of any significance between the L. monocytogenes counts of cheese packed with lysozyme containing zein films and lysozyme, catechin and gallic acid zein films showed that the phenolic compounds had no contribution to the antimicrobial performance of films in cheese. It appeared that the low molecular weight phenolic compounds diffused rapidly to the internal parts of cheese samples and they lost their effects on the food surface. It was also possible that the phenolic compounds formed complex with the cheese proteins and they lost their antimicrobial potential. On the other hand, it is important to report that the cheese samples actively packed with zein-carnauba wax composites containing lysozyme, catechin and gallic acid had the lowest $L$. monocytogenes counts on the 14th and 28th days of cold-storage $(P<0.05)$. The indicated cheese samples were also the only samples showing a significant reduction ( 0.4 decimals) in their initial L. monocytogenes counts during cold-storage $(P<0.05$ on the 28 th and 56th days). These results clearly showed the beneficial effect of the reduced lysozyme-release rates of zein-carnauba wax composite films on the later stages of cold-storage. In the literature, studies related to active packaging of cheese by films containing lysozyme and having controlled release properties were scarce. However, it is worth to note that Duan et al. (2007) employed commercial lysozyme in active packaging of Mozzarella cheese with chitosan films and enhanced their antimicrobial activity against Pseudomonas fluorescens, Escherichia coli and L. monocytogenes. These workers reported that they obtained a $0.32-1.50 \mathrm{log}$ reduction in $L$. monocytogenes population in actively packed cheese samples. On the other hand, Min et al. (2005) used lysozyme in whey protein isolate films and coatings to inhibit the growth of L. monocytogenes in cold-smoked salmon. Similarly, Datta, Janes, Xue, Losso, and La Peyre (2008) used oyster lysozyme and commercial hen egg white lysozyme alone or in combination with nisin in calcium alginate coatings to control the growth of $L$. monocytogenes and Salmonella Anatum in refrigerated smoked salmon. All these studies are promising for increased application of lysozyme in active packaging. However, further studies are needed to employ controlled release technology in active packaging and maximize the beneficial effects obtained from antimicrobial and antioxidant biopreservatives.

\subsubsection{Antioxidant potential of films on Kashar cheese}

The TBA values of packed Kashar cheese samples during coldstorage are displayed in Table 3. The most significant increases in TBA values during cold storage occurred in cheese samples which were unpacked, packed with control zein films and packed with zein films containing lysozyme. Although the uncoated cheese samples had higher TBA values than samples packed with zein control films and zein films containing lysozyme, there were no significant differences among TBA

Table 3

Antioxidant effects of active packaging on Kashar cheese.

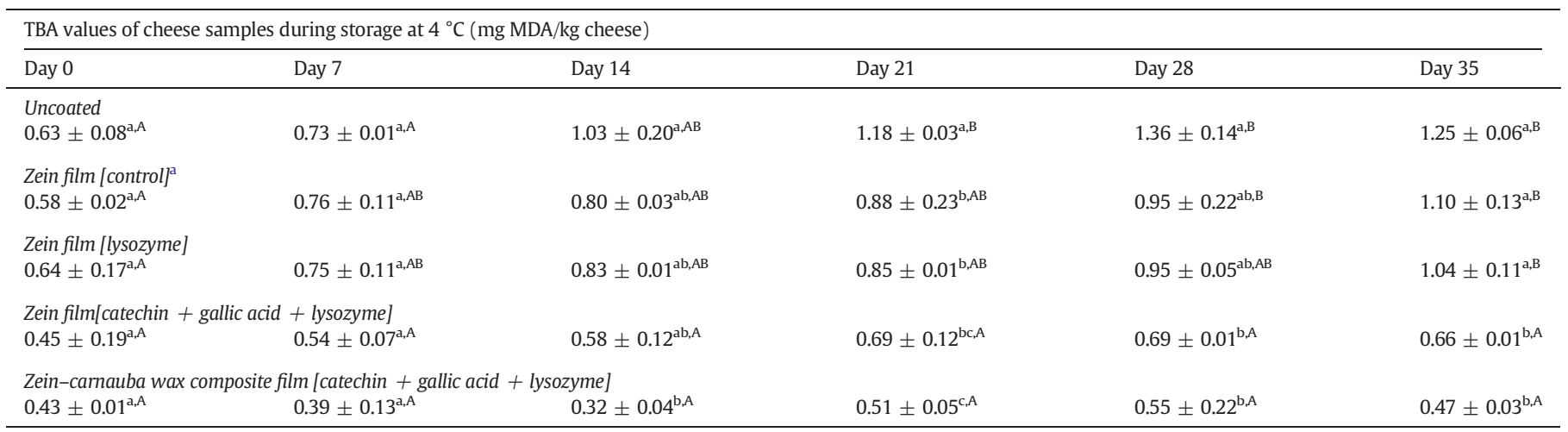

${ }^{\mathrm{a}-\mathrm{C}}$ Values within each storage time followed by the same letter are not significantly different $(P>0.05)$.
${ }^{\mathrm{A}-\mathrm{B} V}$ Values within each treatment followed by the same letter are not significantly different $(P>0.05)$.

a Shows film compositions described in Section 2.6.2. 
of these samples except day 21. Thus, there was no considerable effect of control zein film application alone on oxidative changes in cheese samples. In contrast, the cheese samples packed with zein and zein-carnauba wax composite films containing lysozyme and antioxidant phenolic compounds catechin and gallic acid showed significantly lower lipid oxidation than the uncoated samples, samples packed with control zein films and lysozyme containing zein films at the end of 35 days cold storage $(P<0.05)$. However, there are no statistically significant differences in TBA values of cheeses packed with lysozyme, catechin and gallic acid containing zein and zein-carnauba wax composite films $(P>0.05)$. The limited beneficial effect of the sustained release of phenolic compounds from zein-carnauba wax composite films suggested that the amounts of phenolic compounds released both from zein and zein-carnauba wax composite films is sufficiently high to suppress the oxidative changes in cheese samples within 35 days of cold-storage. In the literature, studies related to active packaging of cheese by edible films containing phenolic compounds and having different phenolic release profiles are scarce. However, it is worth to note the previous successful application of low-density polyethylene films containing synthetic phenolic compound BHT to increase the oxidative stability of cheese (SotoCantú et al., 2008). Moreover, there are different studies which applied rosemary extract containing polypropylene films on beef steaks (Nerin et al., 2006), green tea extract containing chitosan films on pork sausages (Siripatrawan \& Noipha, 2012), thymol, carvacrol, and eugenol containing zein-laminated polyethylene films on ground beef patties (Park et al., 2012), and catechin containing polyvinyl alcohol-starch films on beef (Wu, Wang, \& Chen, 2010). All these studies indicate the great potential of using phenolic antioxidants in antioxidant packaging of dairy and meat products.

\section{Conclusions}

This study clearly showed the effectiveness of lysozyme containing zein and zein-carnauba wax composite films in suppressing the growth of $L$. monocytogenes in fresh cheeses during cold-storage. However, a significant reduction in initial $L$. monocytogenes counts during cold storage occurred only when zein-carnauba wax composite films with sustained lysozyme-release rate were employed in active packaging. The phenolic compounds catechin and gallic acid incorporated into films as multifunctional agents (plasticizer, antioxidant and antimicrobial) did not make any contribution to antilisterial activity of films in cheese, but they plasticized zein films and prevented lipid oxidation in packed cheese samples effectively. However, at the studied active compound concentrations and storage periods the sustained release of phenolic compounds did not show an additional benefit in the control of lipid oxidation. Further studies are needed at different storage conditions with different types of cheeses to evaluate the exact potential of using controlled release technology in the dairy industry.

\section{Acknowledgement}

This work (No. 108M353) was funded by The Scientific and Technical Research Council of Turkey (TÜBITAK). We thank the Materials Research Center and Biotechnology and Bioengineering Research and Applications Center in Izmir Institute of Technology for the generous use of their facilities.

\section{References}

Alkan, D., Aydemir, L. Y., Arcan, I., Yavuzdurmaz, H., Atabay, H. I., Ceylan, C., et al. (2011). Development of flexible antimicrobial packaging materials against Campylobacter jejuni by incorporation of gallic acid into zein-based films. Journal of Agricultural and Food Chemistry, 59(20), 11003-11010.
Appendini, P., \& Hotchkiss, J. H. (2002). Review of antimicrobial food packaging Innovative Food Science \&' Emerging Technologies, 3(2), 113-126.

Arcan, I., \& Yemenicioğlu, A. (2011). Incorporating phenolic compounds opens a new perspective to use zein films as flexible bioactive packaging materials. Food Research International, 44, 550-556.

Arcan, I., \& Yemenicioğlu, A. (2013). Development of flexible zein-wax composite and zeinfatty acid blend films for controlled release of lysozyme. Food Research International, 51(1), 208-216.

ASTM (2002). Standard test method for tensile properties of thin plastic sheeting-D882-02. In ASTM (Ed.), Annual Book of American Standard Testing Methods (Philadelphia, PA).

Bekhit, A. E. D., Geesink, G. H., Ilian, M.A., Morton, J.D., \& Bickerstaffe, R. (2003). The effects of natural antioxidants on oxidative processes and metmyoglobin reducing activity in beef patties. Food Chemistry, 81(2), 175-187.

Datta, S., Janes, M. E., Xue, Q. G., Losso, J., \& La Peyre, J. E. (2008). Control of Listeria monocytogenes and Salmonella anatum on the surface of smoked salmon coated with calcium alginate coating containing oyster lysozyme and nisin. Journal of Food Science, 73(2), M67-M71.

de Castro, V., Escudero, J. M., Rodriguez, J. L., Muniozguren, N., Uribarri, J., Saez, D., et al (2012). Listeriosis outbreak caused by Latin-style fresh cheese, Bizkaia, Spain, August 2012. Eurosurveillance, 17(42) ( pii = 20298).

Duan, J., Park, S. L., Daeschel, M.A., \& Zhao, Y. (2007). Antimicrobial chitosan-lysozyme (CL) films and coatings for enhancing microbial safety of Mozzarella cheese. Journal of Food Science, 72(9), M355-M362.

Han, J. H. (2005). Antimicrobial packaging systems. In H. H. Jung (Ed.), Innovations in food packaging (pp. 80-108). London: Academic Press.

Jackson, K. A., Biggerstaff, M., Tobin-D'Angelo, M., Sweat, D., Klos, R., Nosari, J., et al. (2011) Multistate outbreak of Listeria monocytogenes associated with Mexican-style cheese made from pasteurized milk among pregnant, hispanic women. Journal of Food Protection, 74(6), 949-953.

Joerger, R. D. (2007). Antimicrobial films for food applications: A quantitative analysis of their effectiveness. Packaging Technology and Science, 20(4), 231-273.

Johnsen, B. O., Lingaas, E., Torfoss, D., Strøm, E. H., \& Nordøy, I. (2010). A large outbreak of Listeria monocytogenes infection with short incubation period in a tertiary care hospital. Journal of Infection, 61(6), 465-470.

Kozak, J., Balmer, T., Byrne, R., \& Fisher, K. (1996). Prevalence of Listeria monocytogenes in foods: Incidence in dairy products. Food Control, 7(4-5), 215-221.

Mecitoglu, Ç., Yemenicioglu, A., Arslanoglu, A., Elmacl, Z. S., Korel, F., \& Çetin, A. E. (2006) Incorporation of partially purified hen egg white lysozyme into zein films for antimicrobial food packaging. Food Research International, 39(1), 12-21.

Mendes de Souza, P., Fernández, A., López-Carballo, G., Gavara, R., \& Hernández-Muñoz, P. (2010). Modified sodium caseinate films as releasing carriers of lysozyme. Food Hydrocolloids, 24(4), 300-306.

Min, S., Harris, L. J., Han, J. H., \& Krochta, J. M. (2005). Listeria monocytogenes inhibition by whey protein films and coatings incorporating lysozyme. Journal of Food Protection, 68(11), 2317-2325.

Nerin, C., Tovar, L., Djenane, D., Camo, J., Salafranca, J., Beltran, J. A., et al. (2006). Stabilization of beef meat by a new active packaging containing natural antioxidants. Journal of Agricultural and Food Chemistry, 54(20), 7840-7846.

Padgett, T., Han, I. Y., \& Dawson, P. L. (1998). Incorporation of food-grade antimicrobial compounds into biodegradable packaging films. Journal of Food Protection, 61, 1330-1335.

Park, S. I., Daeschel, M.A., \& Zhao, Y. (2004). Functional properties of antimicrobial lysozyme-chitosan composite films. Journal of Food Science, 69(8), M215-M221.

Park, H. -Y., Kim, S. -J., Kim, K. M., You, Y. -S., Kim, S. Y., \& Han, J. (2012). Development of antioxidant packaging material by applying corn-zein to LLDPE film in combination with phenolic compounds. Journal of Food Science, 77(10), E273-E279.

Singleton, V. L., \& Rossi, J. A., Jr. (1965). Colorimetry of total phenolics with phosphomolybdic-phosphotungstic acid reagents. American Journal of Enology and Viticulture, 16(3), 144-158.

Siripatrawan, U., \& Noipha, S. (2012). Active film from chitosan incorporating green tea extract for shelf life extension of pork sausages. Food Hydrocolloids, 27(1), $102-108$.

Soto-Cantú, C. D., Graciano-Verdugo, A. Z., Peralta, E., Islas-Rubio, A.R., González-Córdova, A., González-León, A., et al. (2008). Release of butylated hydroxytoluene from an active film packaging to Asadero cheese and its effect on oxidation and odor stability. Journal of Dairy Science, 91(1), 11-19.

Ünalan, İ. U., Korel, F., \& Yemenicioğlu, A. (2011). Active packaging of ground beef patties by edible zein films incorporated with partially purified lysozyme and Na2EDTA. International Journal of Food Science and Technology, 46(6), 1289-1295.

Wu, J. -G., Wang, P. -J., \& Chen, S.C. (2010). Antioxidant and antimicrobial effectiveness of catechin-impregnated PVA-starch film on red meat. Journal of Food Quality, 33(6), $780-801$.

Xu, B. J., \& Chang, S. K. C. (2007). A comparative study on phenolic profiles and antioxidant activities of legumes as affected by extraction solvents. Journal of Food Science, 72(2), S159-S166.

Yde, M., Naranjo, M., Mattheus, W., Stragier, P., Pochet, B., Beulens, K., et al. (2012) Usefulness of the european epidemic intelligence information system in the management of an outbreak of listeriosis, Belgium, 2011. Eurosurveillance, $17(38)(\mathrm{pii}=20279)$. 